\title{
Integrated catalytic and electrocatalytic conversion of substituted phenols and diaryl ethers
}

\author{
Yang Song, ${ }^{1}$ Shao Hua Chia, ${ }^{1}$ Udishnu Sanyal, ${ }^{1}$ Oliver Y. Gutiérrez, ${ }^{1 *}$ Johannes A. \\ Lercher $^{1,2 *}$
}
${ }^{1}$ TU München, Department of Chemistry and Catalysis Research Center, Lichtenbergstrasse 4, D-84747 Garching (Germany)
${ }^{2}$ Institute for Integrated Catalysis, Pacific Northwest National Laboratory, P.O. Box 999, Richland, WA 99352 (USA)

${ }^{*}$ Corresponding authors:

Oliver.Gutierrez@mytum.de

Tel. 004989 28912827, Fax 00498928913544

Johannes.Lercher@ch.tum.de

Tel. 00498928913540 , Fax 00498928913544

\begin{abstract}
Electrocatalytic hydrogenation and catalytic thermal hydrogenation of substituted phenols and diaryl ethers were studied on carbon-supported $\mathrm{Rh}$. The rates of electrocatalytic hydrogenation increase with increasingly negative potentials, which have been related with the coverage of adsorbed hydrogen. The lowest and highest negative potentials in electrocatalytic hydrogenation correspond to the onset of $\mathrm{H}_{2}$ evolution and to the onset of reactions involving the electrolyte, respectively. For electrocatalytic and catalytic thermal hydrogen addition reactions, the dominant reaction pathway is hydrogenation to cyclic alcohols and cycloalkyl ethers. The presence of substituting methyl or methoxy groups led to lower rates compared to unsubstituted phenol or diphenyl ether. Methoxy or benzyloxy groups, however, undergo $\mathrm{C}-\mathrm{O}$ bond cleavage via hydrogenolysis and hydrolysis (minor pathway). The surface chemical potential of hydrogen can be increased also by generating a $\mathrm{H}_{2}$ atmosphere above the reaction media, supporting the conclusion that thermal and electrochemical routes share the same reaction pathways.
\end{abstract}

Keywords: Hydrogenation, electrocatalysis, biomass conversion, mild reaction conditions. 


\section{Introduction}

Electrocatalytic hydrogenation of biomass feedstocks is a promising approach for the synthesis of zero-carbon-footprint energy carriers by coupling electrocatalytic $\mathrm{H}^{+}$reduction using renewable energy with reductive processing of biomass-derived intermediates to fuels. In order to realize such a pathway, the synthesis has to occur decentralized, as the renewable electric energy is generated decentralized and with relatively low power. The local, small-scale reductive conversions must be performed under milder conditions than typical hydrotreating processes [1-8].

Formally, electrocatalytic hydrogenation consists of integrating the reduction of protons (Reaction I) and the hydrogenation of organic compounds at the cathode. The reduction at the cathode occurs, while $\mathrm{O}_{2}$ (Reaction II) is formed or another oxidation reaction occurs at the anode.

$$
\begin{array}{ll}
2 \mathrm{H}_{(\mathrm{aq})}^{+}+2 \mathrm{e}^{-} \rightarrow \mathrm{H}_{2(\mathrm{~g})} & \mathrm{E}^{0}=0 \mathrm{~V} \\
2 \mathrm{H}_{2} \mathrm{O}_{(\mathrm{I})} \rightarrow \mathrm{O}_{2(\mathrm{~g})}+4 \mathrm{H}^{+}+4 \mathrm{e}^{-} & \mathrm{E}^{0}=1.23 \mathrm{~V}
\end{array}
$$

Mechanistically, electrocatalytic hydrogenation (ECH) could proceed through two main different pathways, i.e., stepwise proton/electron addition or simultaneous electron-proton (neutral) hydrogenation. In turn, the stepwise hydrogenation may consist of electron addition followed by protonation of the oxygenated hydrocarbon, or by direct protonation of the hydrocarbon followed by electron transfer. Direct electron addition to an aromatic hydrocarbon followed by proton addition is not likely, because higher negative overpotentials are required for the direct reduction of aromatic molecules than for proton reduction, as shown, e.g., for the reduction of benzene in Reaction III [9]. A pathway started by protonation of the aromatic would depend on the strength of the acid present in the environment and the proton affinity of the hydrocarbon in solution. We can rule out such a pathway for phenolic compounds (model molecules used in this study), because the $\mathrm{pK}_{\mathrm{a}}$ of, e.g., protonated phenol and protonated benzene are -6 and -24 , respectively. Thus, very high activation barriers are expected in stepwise hydrogenation mechanisms, compared to neutral pathways [10].

$$
\mathrm{C}_{6} \mathrm{H}_{6}+\mathrm{e}^{-} \rightarrow\left(\mathrm{C}_{6} \mathrm{H}_{6}\right)^{-} \quad \mathrm{E}^{0}=-3.18 \mathrm{~V}
$$

The mechanistic steps for the cathode reaction in water electrolysis comprise of the formation of adsorbed $\mathrm{H}$ (Volmer step, Reactions IV and V), the combination of $\mathrm{H}$ to $\mathrm{H}_{2}$ (Tafel step, Reaction $\mathrm{VI}$ ) and the concerted reductive $\mathrm{H}_{2}$ production (Heyrovsky steps, Reactions VII and VIII).

$\mathrm{H}^{+}+\mathrm{e}^{-} \rightleftharpoons \mathrm{H}_{\mathrm{ads}}$ (in acid) 
$\mathrm{H}_{2} \mathrm{O}+\mathrm{e}^{-} \rightleftharpoons \mathrm{H}_{\mathrm{ads}}+\mathrm{OH}^{-}$(in base)

$2 \mathrm{H}_{\mathrm{ads}} \rightleftharpoons \mathrm{H}_{2}$

$\mathrm{H}_{\mathrm{ads}}+\mathrm{H}^{+}+\mathrm{e}^{-} \rightleftharpoons \mathrm{H}_{2}$ (in acid)

$\mathrm{H}_{\mathrm{ads}}+\mathrm{H}_{2} \mathrm{O}+\mathrm{e}^{-} \rightleftharpoons \mathrm{H}_{2}+\mathrm{OH}^{-}$(in base)

The simultaneous electron-proton transfer to the hydrocarbon as hydrogenation mechanism may proceed via concerted electron-proton transfer or via $\mathrm{H}$-atom transfer $[11,12]$. Reaction IX exemplifies a first concerted hydrogenation step to adsorbed phenol, whereas Reaction $\mathrm{X}$ shows the hydrogenation of phenol to cyclohexanone by $\mathrm{H}$ atoms. It is difficult to determine unequivocally the nature of the hydrogenation step. However, phenol can be hydrogenated at the metal surface with adsorbed $\mathrm{H}$ in the absence of electric potential [13]. Thus, under our conditions, the hydrogenation pathway is hypothesized at this point to be equivalent to the thermally induced catalyzed reaction between $\mathrm{H}_{2}$ and the reactant thermal hydrogenation (thermal catalytic hydrogenation, TCH). In this instance, the (reversible) Volmer step, would establish the surface chemical potential of $\mathrm{H}$ that drives the hydrogenation and product desorption.

$\mathrm{C}_{6} \mathrm{H}_{5} \mathrm{OH}^{*}+\mathrm{H}^{+}+\mathrm{e}^{-} \rightarrow \mathrm{C}_{6} \mathrm{H}_{6} \mathrm{OH}^{*}$

$\mathrm{C}_{6} \mathrm{H}_{5} \mathrm{OH}+4 \mathrm{H}_{\mathrm{ads}} \rightarrow \mathrm{C}_{6} \mathrm{H}_{10} \mathrm{O}$

Therefore, the $\mathrm{ECH}$ in this case is equivalent to the metal catalyzed hydrogenation of hydrocarbons in aqueous phase with the adsorbed hydrogen generated in situ. $\mathrm{ECH}$ of phenol has been reported on $\mathrm{Pd}-$, Ni-, and Rh-based catalysts [13-15]. C-O bond cleavage has been observed for the electrochemical conversion of benzophenone, diaryl ethers, and hydroxymethylfurfural $[15,16]$. However, the reaction pathways, mechanisms that operate at such mild conditions and the impact of the molecular structure on the pathways have hardly been explored. A detailed molecular level understanding of the reaction pathways is required to advance this important reaction step in an overall concept of a decentralized synthesis of carbon-neutral fuels.

As a step in this direction, we report here on the catalytic hydrogenation of increasingly complex aromatic molecules containing oxygen, ranging from phenol to substituted di-aryl ethers on carbon-supported $\mathrm{Rh}(\mathrm{Rh} / \mathrm{C})$. We compare reaction pathways and kinetic parameters obtained when the adsorbed hydrogen is formed from proton reduction $(\mathrm{ECH})$ or $\mathrm{H}_{2}$ dissociation (TCH).

\section{Methods}


A comprehensive list of chemical and materials used in our experiments is provided in the supporting information. The characterization of the catalytic material, $\mathrm{Rh}$ supported on $\mathrm{C}$ is also described in the supporting information. In the following we describe the experimental methods for electrocatalytic hydrogenation $(\mathrm{ECH})$, and thermal catalytic hydrogenation $(\mathrm{TCH})$. The geometrical surface area of the carbon felt electrode $(30 \mathrm{~mm} \cdot 15 \mathrm{~mm} \cdot 6 \mathrm{~mm}$ ) was 9.54 $\mathrm{cm}^{2}$. However, we considered the real electrode area as the metal surface area determined by $\mathrm{H}_{2}$ chemisorption measurements (supporting information). That is, $88 \mathrm{~m}^{2} \cdot \mathrm{g}$ or $880 \mathrm{~cm}^{2}$ of $\mathrm{Rh}$ in $20 \mathrm{mg}$ catalyst, typically used in the experiments.

\section{Electrocatalytic hydrogenation (ECH)}

In a previous contribution, $\mathrm{ECH}$ was slower than $\mathrm{TCH}$ by one order of magnitude [10]. The reason for the low rates of was the particular experimental configuration in which the large distance between electrodes and the concomitant resistance to ion transport led to significant voltage losses. In order to minimize internal Ohmic resistance, in this work all experiments were carried out in a two-compartment galvanostatic cell with very short distance between electrodes and the membrane. A diagram of the cell used to perform the reactions is shown in Figure S1. Cathodic and anodic compartments of the cell were separated by a Nafion 117 proton exchange membrane (Ion Power, Inc.), which was pretreated in a $\mathrm{H}_{2} \mathrm{O}_{2}$ solution (3 vol.\%) and in sulfuric acid (2 M) before reaction. A piece of carbon felt (Alfa Aesar $>99.0 \%$, $3.2 \mathrm{~mm}$ thickness, shown in Figure S2) connected to a graphite rod (Sigma Aldrich) was used as working electrode in the cathode compartment. A platinum wire (Alfa Aesar, $99.9 \%$ ) was used as counter electrode in the anodic compartment. The reference electrode was a home-made $\mathrm{Ag} / \mathrm{AgCl}$ electrode with a double junction. For $\mathrm{ECH}$ of phenol, methylphenol and methoxyphenol, the cathode compartment was filled with acetate buffer at $\mathrm{pH} 5.20 \mathrm{mg}$ of the $\mathrm{Rh} / \mathrm{C}$ catalyst were added into the cathode compartment. All reactions were performed at atmospheric pressure at $296 \mathrm{~K}$. The stirring at $500 \mathrm{rpm}$ allowed complete incorporation of the powder into the carbon felt. Prior to $\mathrm{ECH}$, polarization of the catalyst was performed under a constant current of $-40 \mathrm{~mA}$ for $30 \mathrm{~min}$. For $\mathrm{ECH}$, phenolic solution was added into the cathode compartment to obtain a final concentration of $16 \mathrm{mmol} / \mathrm{L}$. Owning to the poor solubility of di-aryl ethers in water at room temperature a mixture of acetate buffer (30 vol.\%) in isopropanol was used as solvent for $\mathrm{ECH}$ of diphenyl ether, p-tolyl ether, and benzyl phenyl ether. For the $\mathrm{ECH}$ of these compounds, solutions with $5 \cdot 10^{-4}$ mol reactants were mixed with $50 \mathrm{mg}$ of $\mathrm{Rh} / \mathrm{C}$. ECH experiments were performed at constant potential while a flow of $\mathrm{He}$ was kept through the cell. During all described procedures, the anode compartment contained mixtures of acetate buffer $(\mathrm{pH} 5)$ as the electrolyte. All electrochemical procedures were performed with an electrochemical workstation (VSP-300, Bio Logic). Before each ECH test, the cell compartments and other materials were cleaned with concentrated $\mathrm{H}_{2} \mathrm{SO}_{4}$ and immersed in boiling water for $2 \mathrm{~h}$ several times. Prior to the 
reactions, the electrodes were alternatively immersed in $\mathrm{H}_{2} \mathrm{SO}_{4}(5 \mathrm{M})$ and $\mathrm{KOH}(5 \mathrm{M})$ for 15 min. After each immersion, the materials were thoroughly cleaned (Pt electrodes were further ultrasonically treated) in ultrapure water for $15 \mathrm{~min}$. $\mathrm{ECH}$ with recycling hydrogen were performed in the cell depicted in as Figure S1. The cell was closed gas-tight and equipped with a recycling gas pump on top of the cathodic chamber to recycle the hydrogen produced via hydrogen evolution reaction during $\mathrm{ECH}$.

Thermal catalytic hydrogenation (TCH)

Catalytic thermal reactions were carried out at atmospheric pressure with $\mathrm{H}_{2}(20 \mathrm{~mL} / \mathrm{min})$ flowing through the reactant solution in the cathode compartment at $296 \mathrm{~K}$. The preparation of the different reactant solutions and their concentrations were the same as those described for $\mathrm{ECH}$. For coupled $\mathrm{ECH}$ and $\mathrm{TCH}$ experiments, a recycling pump was connected to the cell in order to feed in the $\mathrm{H}_{2}$ produced by the hydrogen evolution reaction, whereas the cell was closed to allow building up of the pressure.

Product analysis

The course of the $\mathrm{ECH}$ and $\mathrm{TCH}$ experiments was followed by periodically withdrawing aliquots of $1 \mathrm{~mL}$ from the cathode compartment. The products were extracted with $3 \mathrm{~mL}$ of ethyl acetate. A $2 \mathrm{~mL}$ of $1 \mathrm{~mol} / \mathrm{L} \mathrm{Na}_{2} \mathrm{SO}_{4}$ solution was needed for the extraction of diaryl ethers, owning to the presence of ethanol in the solution. The organic phase was separated from the aqueous phase by decantation and dried on $\mathrm{Na}_{2} \mathrm{SO}_{4}$. A sample of the dry organic phase was mixed with a solution containing a standard. Quantitative analyses of those samples were performed by gas chromatography coupled with mass spectrometry (Shimadzu GCMS-QP2010), equipped with a plot Q capillary column (30m x $250 \mu \mathrm{m})$ and a thermal conductivity detector (TCD).

\section{Results and discussion}

The catalyst used in this work was carbon-supported Rh with a metal loading of 5 wt.\% and average $\mathrm{Rh}$ particle size of $3.4 \mathrm{~nm}$. During the experiments, this catalyst was infiltrated in an activated carbon felt. Experimental procedures (Figures S1), calculation details, and catalyst characterization (Figures S2) are described in the supporting information. In the following the Faradaic efficiencies (FE) is defined as the percentage of the current producing the adsorbed hydrogen that reacts with oxygenates, i.e., reactant and intermediates of $\mathrm{ECH}$. The turnover frequencies (TOF) correspond to the moles of $\mathrm{ECH}$ reactant converted per surface metal atom per hour. $\mathrm{ECH}$ and rates of the hydrogen evolution reaction (HER) are defined as the moles of organic reactant converted and moles of molecular $\mathrm{H}_{2}$ produced, respectively, per second and gram of Rh. Adsorbed hydrogen $\left(\mathrm{H}_{\mathrm{ads}}\right)$ consumption rates of $\mathrm{ECH}, \mathrm{TCH}$, and 
$\mathrm{HER}$ are defined as the moles of adsorbed $\mathrm{H}$ that react with organic compounds via $\mathrm{ECH}$ or $\mathrm{TCH}$ or that produce molecular $\mathrm{H}_{2}$ in HER, respectively, per second and gram of Rh.

\section{Manipulating the electrocatalytic hydrogenation of phenol with potential}

In the conversion of phenol at varying potentials, the cathodic current increased linearly from $18 \mathrm{~mA}$ to $220 \mathrm{~mA}$ with potentials varying from $-0.4 \mathrm{~V}$ to $-0.9 \mathrm{~V}$ ( $\mathrm{vs} \mathrm{Ag} / \mathrm{AgCl}$ ) (Table 1$)$. In this potential range, the sum of hydrogen reacted with oxygenates and evolved as $\mathrm{H}_{2}$ (only product detected in the gas phase) equaled the measured currents. Thus, electrons were only consumed in the reduction of protons, which solely participate in $\mathrm{ECH}$ as well as in HER. The ohmic loss was $1.8 \mathrm{Ohm}$ as determined by impedance measurements. Upon taking into account this loss, the current showed an exponential increase with increasingly negative HFR-free potentials as shown in Table S2 and Figure S3.

Table 1. Measured current, current density, rate of electrocatalytic hydrogenation $(E C H)$, TOF, Faradaic efficiency (FE), and rates of hydrogen evolution (HER) observed during the catalytic hydrogenation of phenol at varying potentials. The reactions were performed in mixtures of water and acetic acid at room temperature and atmospheric pressure on $\mathrm{Rh} / \mathrm{C}$.

\begin{tabular}{lcccccc}
\hline Potential $(\mathrm{V} \mathrm{vs} \mathrm{Ag} / \mathrm{AgCl})$ & -0.4 & -0.5 & -0.6 & -0.7 & -0.8 & -0.9 \\
\hline Current $(\mathrm{mA})$ & -18 & -50 & -100 & -140 & -175 & -220 \\
Current density ${ }^{\mathrm{a}}\left(\mathrm{mA} \cdot \mathrm{cm}^{-2}\right)$ & 0.02 & 0.06 & 0.11 & 0.16 & 0.20 & 0.25 \\
ECH $\left(\cdot 10^{-5} \mathrm{~mol} \cdot \mathrm{s}^{-1} \cdot \mathrm{g}_{\mathrm{Rh}}{ }^{-1}\right)$ & 0.81 & 7.5 & 16 & 26 & 28 & 34 \\
TOF $\left(\mathrm{h}^{-1}\right)$ & 15 & 138 & 296 & 475 & 538 & 629 \\
FE $(\%)$ & 20 & 58 & 68 & 70 & 68 & 66 \\
HER $\left(\cdot 10^{-5} \mathrm{~mol} \cdot \mathrm{s}^{-1} \cdot \mathrm{g}_{\mathrm{Rh}}{ }^{-1}\right)$ & 7.5 & 11 & 16 & 22 & 29 & 38 \\
\hline
\end{tabular}

a The electrode area is defined as the metal surface as determined via $\mathrm{H}_{2}$ chemisorption.

For comparison, the rates of hydrogen equivalents consumed during $\mathrm{ECH}$ (converting the reactant and intermediate) and during HER are shown in Figure 1 (for values see Table S3). The low rates of $\mathrm{ECH}$ and $\mathrm{HER}$ at $-0.4 \mathrm{~V}$ are caused by the overpotential needed for generating surface hydrogen at $\mathrm{pH}$ of $4.6(-0.45 \mathrm{~V}$ vs $\mathrm{Ag} / \mathrm{AgCl})$. Between $-0.4 \mathrm{~V}$ and $-0.9 \mathrm{~V}$, the changes of $\mathrm{HER}$ and $\mathrm{ECH}$ rates with potential increased linearly with $3 \mu \mathrm{molH}_{\mathrm{ads}} \cdot \mathrm{s}^{-1} \cdot \mathrm{g}_{\mathrm{Rh}}{ }^{-1}$ of $\mathrm{H}$ consumed in HER and $1.2 \mu \mathrm{molH}_{\mathrm{ads}} \cdot \mathrm{s}^{-1} \cdot \mathrm{g}_{\mathrm{Rh}}{ }^{-1}$ of $\mathrm{H}$ consumed in $\mathrm{ECH}\left(0.61 \mu \mathrm{mol} \cdot \mathrm{s}^{-1} \cdot \mathrm{g}_{\mathrm{Rh}}{ }^{-1}\right.$ of $\mathrm{H}_{2}$ evolved and $0.68 \mu \mathrm{mol} \cdot \mathrm{s}^{-1} \cdot \mathrm{g}_{\mathrm{Rh}}{ }^{-1}$ of phenol converted), per $1 \mathrm{mV}$ of negative potential. $\mathrm{ECH}$ rates increasing faster than HER rates with increasing negative potentials suggesting a surprisingly stronger dependence of phenol hydrogenation than HER on concentration of adsorbed hydrogen. 


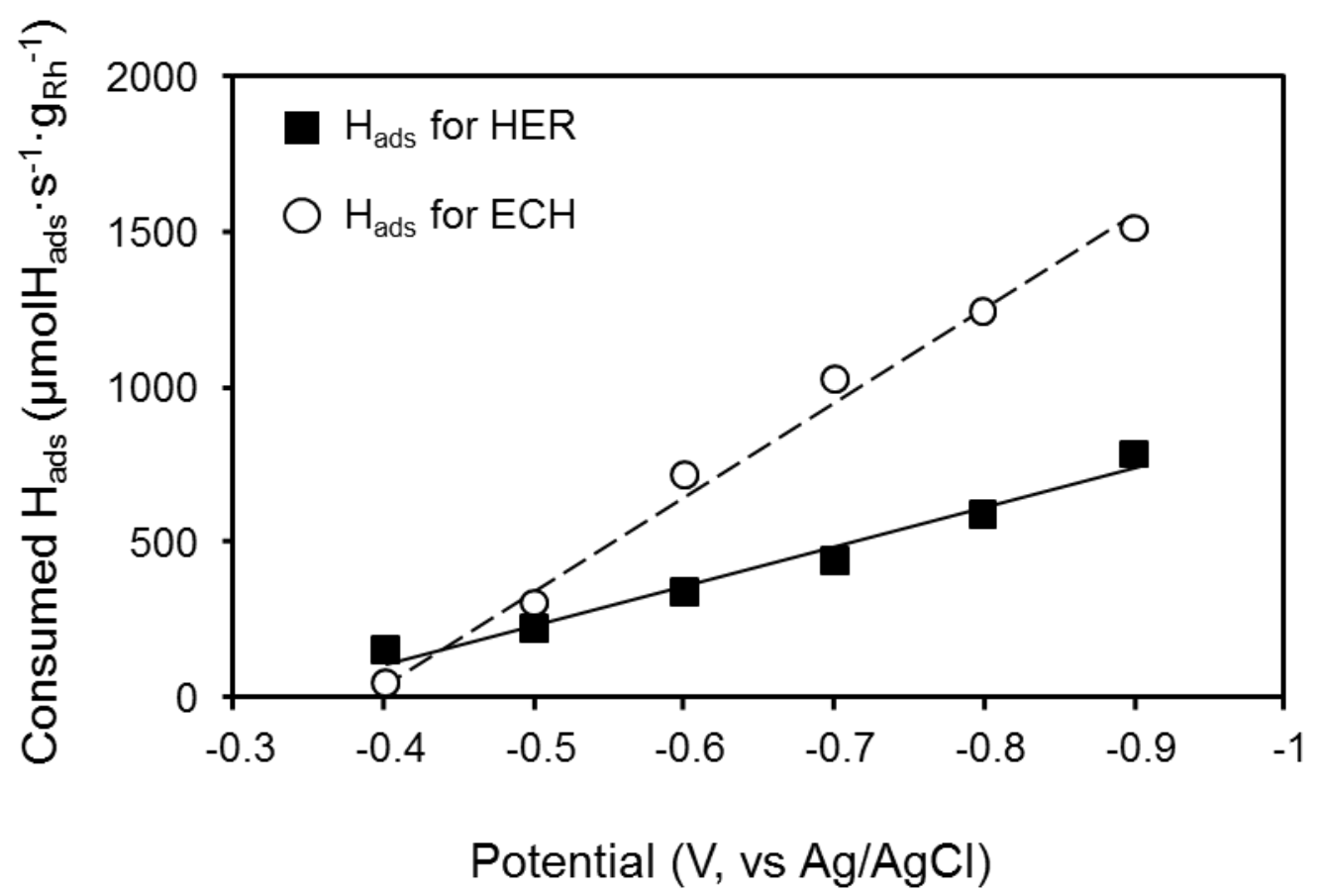

Figure 1. Dependence of electrocatalytic phenol hydrogenation $(E C H)$ and hydrogen evolution rates (HER), expressed as rate of adsorbed hydrogen consumed, on potential. The reactions were performed in a water-acetic acid mixture at room temperature and atmospheric pressure on $\mathrm{Rh} / \mathrm{C}$.

The rate of $\mathrm{H}$ addition to oxygenates in TCH was $10 \cdot 10^{-4} \mathrm{molH}_{\mathrm{ads}} \cdot\left(\mathrm{s} \cdot \mathrm{g}_{\mathrm{Rh}}\right)^{-1}\left(\mathrm{TOF}\right.$ of $\left.385 \mathrm{~h}^{-1}\right)$ at $298 \mathrm{~K}$ and 1 bar $\mathrm{H}_{2}$ (Figure 2). In ECH, the conversion of the organic compounds was controlled by potential and could reach rates, which were up to 1.6 times higher than $\mathrm{TCH}$ at a $\mathrm{H}_{2}$ pressure of 1 bar, i.e., $15 \cdot 10^{-4} \mathrm{molH}_{\mathrm{ads}} \cdot\left(\mathrm{s} \cdot \mathrm{g}_{\mathrm{Rh}}\right)^{-1}\left(\right.$ TOF of $\left.629 \mathrm{~h}^{-1}\right)$ at $-0.9 \mathrm{~V}$.

The reaction order in phenol from $-0.4 \mathrm{~V}$ to $-0.9 \mathrm{~V}$ was zero (Figure 2). Thus, the coverage of reactive hydrogen on the metal surface determines the $\mathrm{ECH}$ rates. In turn, faster $\mathrm{ECH}$ than $\mathrm{TCH}$ implies that the concentration of adsorbed $\mathrm{H}$ under $\mathrm{ECH}$ is higher than the equilibrium value corresponding to 1 bar $\mathrm{H}_{2}$. 


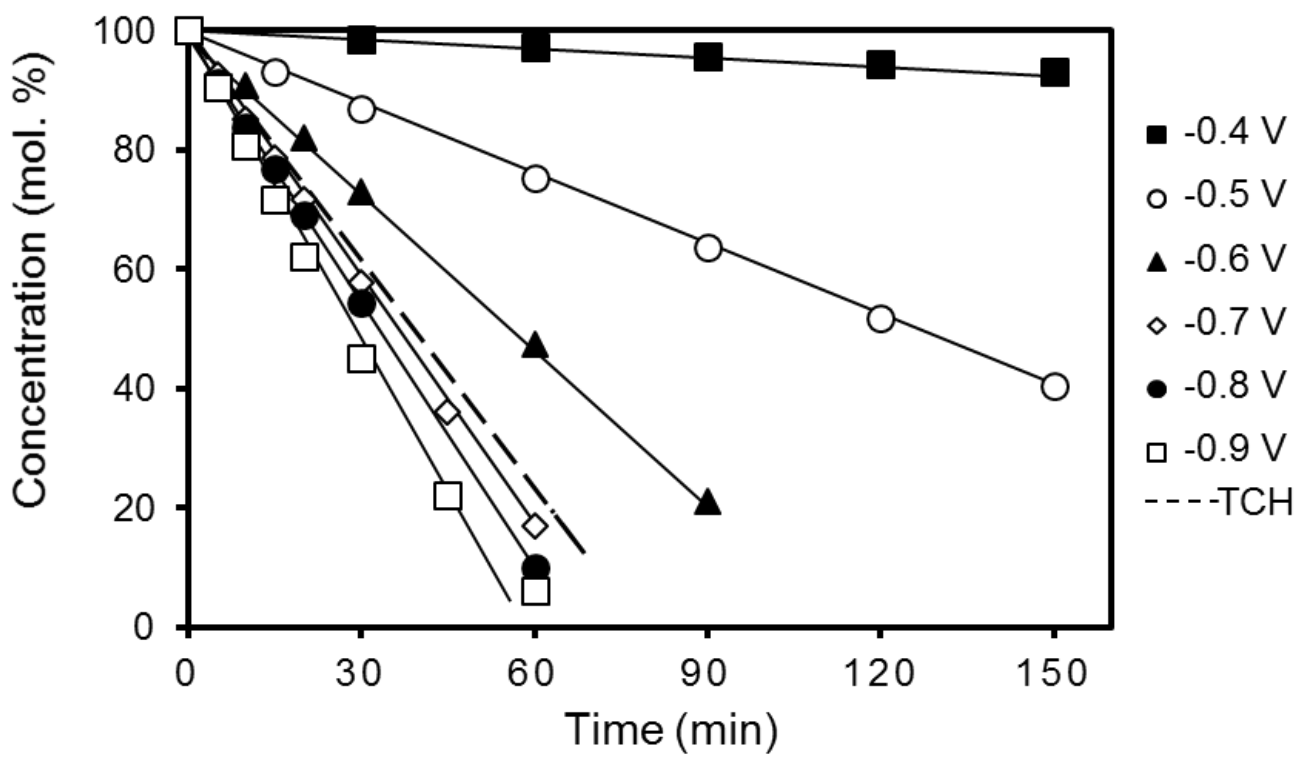

Figure 2. Decrease in phenol concentration during thermal catalytic hydrogenation (TCH), and electrocatalytic hydrogenation under varying potentials (from $-0.4 \mathrm{~V}$ to $-0.9 \mathrm{~V}$ vs $\mathrm{Ag} / \mathrm{AgCl}$ ). The reactions were conducted in a water-acetic acid mixture at room temperature and atmospheric pressure on $\mathrm{Rh} / \mathrm{C}$.

At conditions where only HER occurs (Reaction I), the hydrogen coverage at the metal surface at $-0.23 \mathrm{~V}$ (or $-0.52 \mathrm{~V}$ at $\mathrm{pH} 5$ ), vs $\mathrm{Ag} / \mathrm{AgCl}$ is equivalent to 1 bar of $\mathrm{H}_{2}$ gas. However, the $\mathrm{ECH}$ conditions are far from ideal, as protons must compete with hydrocarbons for adsorbing at the metal, where $\mathrm{H}$ recombination occurs in parallel to hydrogenation. This has to require high over potentials to sustain hydrogen coverages. Follow this rationale, if the role of the potential in $\mathrm{ECH}$ is to provide the adsorbed hydrogen that reacts with phenol, $a$ potential must exist (more negative than that required for ideal HER) at which the hydrogen coverage is identical to that corresponding to 1 bar of $\mathrm{H}_{2}$ in the presence of the hydrocarbon. We identified $-0.7 \mathrm{~V}$ as that potential, because all rates of $\mathrm{TCH}$ and $\mathrm{ECH}$ of the reaction of intermediates were similar at that point (Figure 2). Figure 3 shows that the concentration profiles of $\mathrm{TCH}$ and $\mathrm{ECH}$ at $-0.7 \mathrm{~V}$ were equivalent. In contrast, the concentration profiles of $\mathrm{TCH}$ and $\mathrm{ECH}$ at e.g., $-0.6 \mathrm{~V}$ are clearly different. The cyclohexanol to cyclohexanone molar ratio at, e.g., $\sim 20 \%$ phenol conversion, increased from 0.31 to 0.4 with increasingly negative potentials. This shows that increasing hydrogen coverage enhances the production of cyclohexanol, which is formed after addition of $6 \mathrm{H}$ to the initial reactant phenol. 

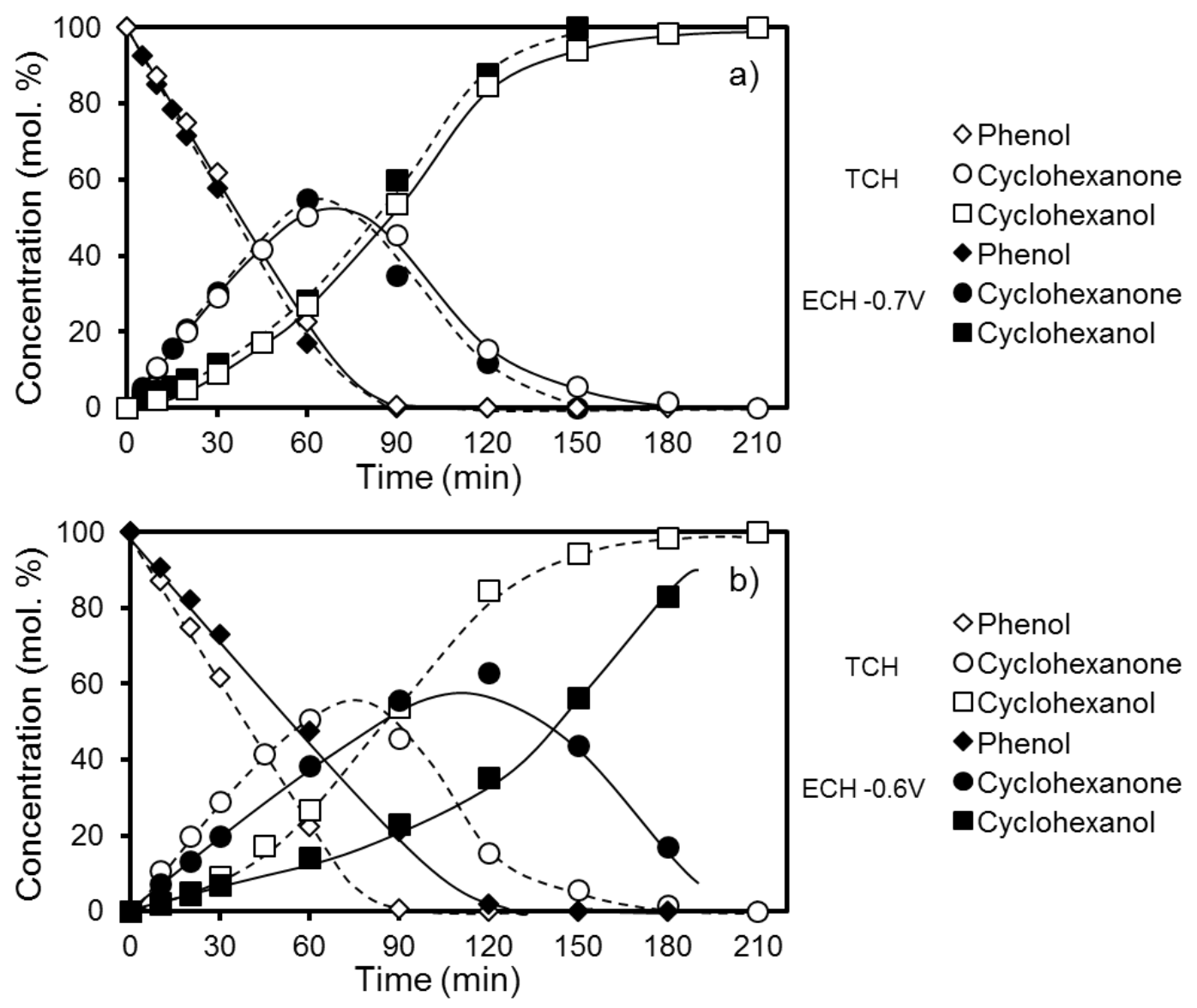

Figure 3. Concentration profiles observed during thermal catalytic hydrogenation (TCH) and electrocatalytic hydrogenation $(\mathrm{ECH})$ of phenol. a) Comparison between $\mathrm{TCH}$ and $\mathrm{ECH}$ at $0.7 \mathrm{~V}, \mathrm{~b})$ comparison between $\mathrm{TCH}$ and $\mathrm{ECH}$ at $-0.6 \mathrm{~V}(\mathrm{vs} \mathrm{Ag} / \mathrm{AgCl})$.

\section{Electrocatalytic hydrogenation and catalytic thermal hydrogenation of substituted phenolic compounds}

The conversion rates of methylphenol and methoxyphenol were lower than that of phenol under identical $\mathrm{TCH}$ and $\mathrm{ECH}$ conditions (Table 2). In ECH, the FEs of methylphenol and methoxyphenol were lower than the ones observed of phenol at the same potential, whereas the observed currents did not vary significantly. This indicates that the surface concentration of the hydrocarbons decreased with increasing substitutions, allowing for the rates of HER to increase twofold compared to the HER parallel to the ECH of phenol (Table 2). Indeed, the presence of a methyl or methoxy group decreases the adsorption energy of the aromatic compound on noble metals by $10-30 \mathrm{~kJ} \cdot \mathrm{mol}^{-1}$ [17]. This effect is caused by repulsive interactions between the substituent groups and the metal surface, whereas their induction effect on the adsorption of the ring is minor. In agreement with this, we observed that the position of the substituents $(o, m$, or $p$ ) had a small influence on the hydrogenation rates (Table S4 and Figure S4 of the supporting information). 
Table 2. Potential, current, current density, reaction rate, TOF, and Faradaic efficiency observed during the conversion of phenol, 4-methylphenol, and 4-methoxyphenol during $\mathrm{ECH}$ and $\mathrm{TCH}$. The reactions were performed in a water-acetic acid mixture at room temperature and atmospheric pressure on $\mathrm{Rh} / \mathrm{C}$.

\begin{tabular}{|c|c|c|c|c|c|c|}
\hline & \multicolumn{2}{|c|}{ Phenol } & \multicolumn{2}{|c|}{ 4-Methylphenol } & \multicolumn{2}{|c|}{ 4-Methoxylphenol } \\
\hline & $\mathrm{ECH}$ & $\mathrm{TCH}$ & $\mathrm{ECH}$ & $\mathrm{TCH}$ & $\mathrm{ECH}$ & $\mathrm{TCH}$ \\
\hline Potential (V vs Ag/AgCl) & -0.6 & - & -0.6 & - & -0.6 & - \\
\hline Current (mA) & -100 & - & -105 & - & -95 & - \\
\hline Current density $^{\mathrm{a}}\left(\mathrm{mA} \cdot \mathrm{cm}^{-2}\right)$ & 0.11 & & 0.12 & & 0.11 & \\
\hline Reaction rate $\left(\cdot 10^{-5} \mathrm{~mol} \cdot \mathrm{s}^{-1} \cdot \mathrm{g}_{\mathrm{Rh}}^{-1}\right)$ & 16 & 20 & 8.1 & 10 & 7.4 & 11 \\
\hline $\operatorname{TOF}\left(h^{-1}\right)$ & 296 & 374 & 151 & 191 & 138 & 212 \\
\hline $\mathrm{FE}(\%)$ & 68 & - & 31 & - & 35 & - \\
\hline HER rate $\left(\cdot 10^{-5} \mathrm{~mol} \cdot \mathrm{s}^{-1} \cdot \mathrm{g}_{\mathrm{Rh}}{ }^{-1}\right)$ & 17 & - & 38 & - & 32 & - \\
\hline
\end{tabular}

${ }^{\mathrm{a}}$ The electrode area is defined as the metal surface as determined via $\mathrm{H}_{2}$ chemisorption.

Complete removal of $\mathrm{O}$ from hydroxyl groups at room temperature was not observed. This concluded to be absent, because the energy of activation to cleave the $\mathrm{C}-\mathrm{O}$ bond is too high for secondary alcohols $[18,19]$. Thus, the conversion of phenol and methylphenol is limited to hydrogenation to cyclohexanones and cyclic alcohols (Figure S5, and Figure 4a and 4c). The concentrations of cyclohexanones pass through maximum values indicating that they are primary and intermediate products. In contrast, the concentration of alcohols increased exponentially with time indicating that these are stable products [20-22]. Note that the concentration profiles in $\mathrm{TCH}$ and $\mathrm{ECH}$ are not identical, because coverages of adsorbed hydrogen in $\mathrm{TCH}$ and $\mathrm{ECH}$ differ under the experimental conditions. At sufficiently long reaction time, complete conversion of reactant and intermediates was achieved.

The $\mathrm{ECH}$ and $\mathrm{TCH}$ of methoxyphenol produced hydrogenated products, (i.e., methoxy cyclohexanone and methoxy cyclohexanol), as well as phenol, cyclohexanone, cyclohexanol, and methanol (Figure $4 \mathrm{~b}$ and $4 \mathrm{~d}$ ). Thus, the presence of the methoxy group opened a C-O hydrogenolysis pathway, yielding methanol (not reacting under these conditions) and phenol, which reacts further along the hydrogenation pathway described before. The selectivity was $90 \%$ to hydrogenation, and $10 \%$ to hydrogenolysis under $\mathrm{ECH}$ and $\mathrm{TCH}$. 

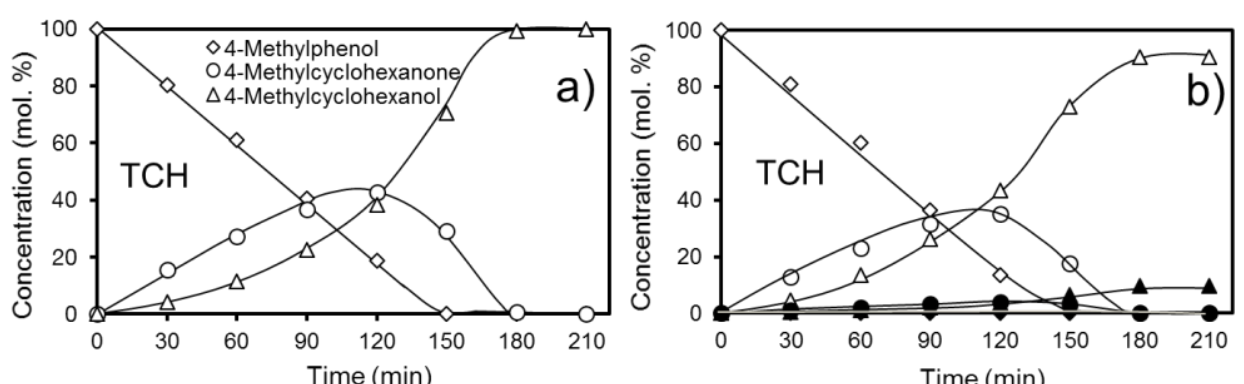

$\diamond 4-$ Methoxyphenol

04-Methoxycyclohexanone

$\triangle 4-M e t h o x y c y c l o h e x a n o l$

Phenol

- Cyclohexanone

$\Delta$ Cyclohexanol
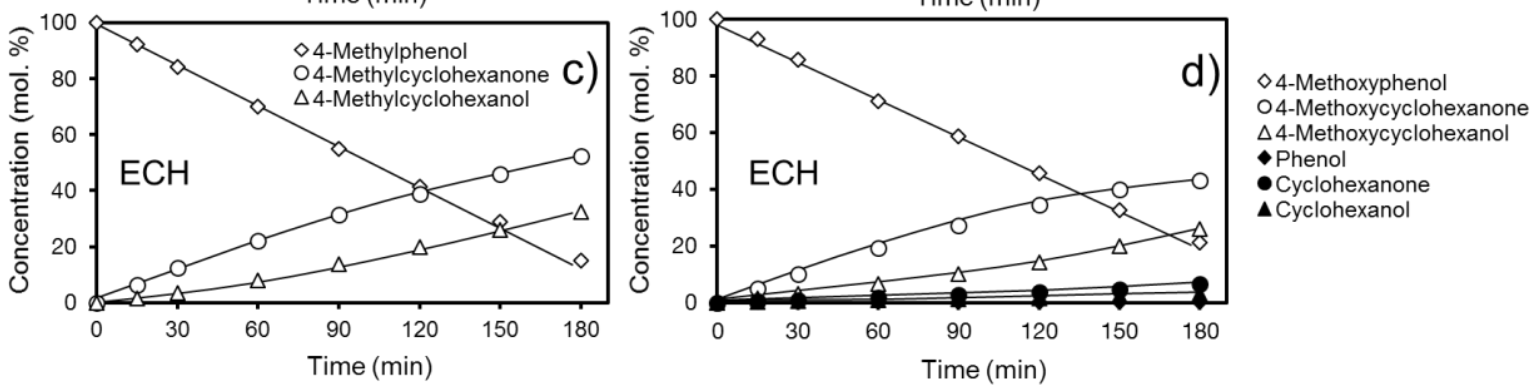

Figure 4. Concentration profiles observed during thermal catalytic hydrogenation (TCH, upper panels) and electrocatalytic hydrogenation (ECH bottom panels) of 4-methylphenol (a, c) and 4-methoxyphenol (b, d). The reactions were performed in water at room temperature and atmospheric pressure on $\mathrm{Rh} / \mathrm{C}$. The potential in $\mathrm{ECH}$ was $-0.6 \mathrm{~V}(\mathrm{vs}$. $\mathrm{Ag} / \mathrm{AgCl})$.

Scheme 1 shows the reaction networks for the conversion of phenolic compounds by $\mathrm{ECH}$ and $\mathrm{TCH}$. The only pathway for phenol, and methyl phenol, and main pathway for methoxyphenol is the consecutive 4- and 2-hydrogen additions to the corresponding cyclohexanones and cyclic alcohols, respectively. 4-Methoxyphenol undergoes C-O bond hydrogenolysis as a minor pathway. We hypothesize that the $\mathrm{C}-\mathrm{O}$ bond was cleaved between the methoxy group and phenol in 4-methoxyphenol due to its lower strength (410 $\mathrm{kJ} \cdot \mathrm{mol}^{-1}$ ) compared to the bond between the hydroxyl group and the aromatic ring (480 $\left.\mathrm{kJ} \cdot \mathrm{mol}^{-1}\right)$. Cleavage of the methoxy group in the hydrogenated products was not observed. 

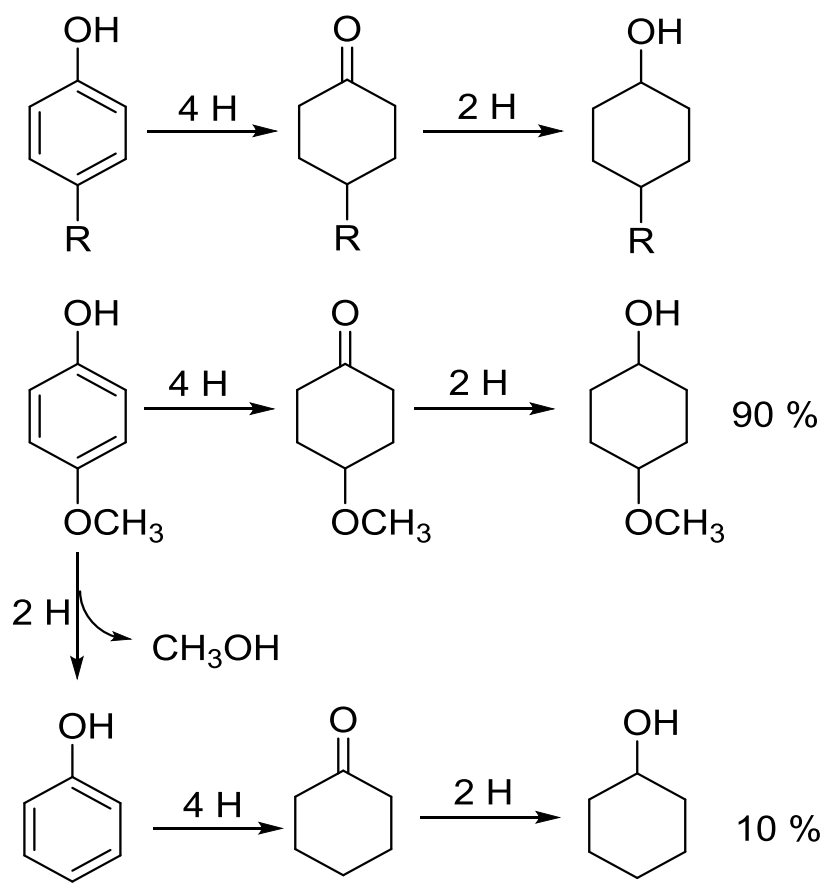

Scheme 1. Reaction networks of the conversion of phenol $(R=H)$ 4-methylphenol $\left(R=\mathrm{CH}_{3}\right)$ (up) and 4-methoxyphenol (bottom) under catalytic thermal hydrogenation and electrocatalytic hydrogenation.

\section{Electrocatalytic hydrogenation and catalytic thermal hydrogenation of di-aryl ethers}

The conversion of the aryl ethers (representative of lignin-derived bio-oils): diphenyl ether (DPE), p-tolyl ether (PTE), and benzyl phenyl ether (BPE), was performed via $\mathrm{TCH}$ and $\mathrm{ECH}$. The supporting information describes the effect of the solvent on rates and the choice of isopropanol-water mixtures as solvent. Under $\mathrm{TCH}$ and $\mathrm{ECH}$ modes, the reactivities of the aryl ethers increased following the ranking PTE < DPE < BPE (Table 3 and Figure S6 of the supported information). PTE is the least reactive, because of the steric repulsion induced by the methyl groups, decreasing the adsorption enthalpy by $75 \mathrm{~kJ} \cdot \mathrm{mol}^{-1}$ compared to DPE [23]. In contrast, the high reactivity of BPE is related to the relatively low dissociation energy of the $\alpha-\mathrm{O}-4$ bond $\left(218 \mathrm{~kJ} \cdot \mathrm{mol}^{-1}\right)$, compared to, e.g., that of the $4-0-5$ bond in DPE $\left(314 \mathrm{~kJ} \cdot \mathrm{mol}^{-1}\right)$.

In $\mathrm{TCH}$ and $\mathrm{ECH}$, the conversion of di-aryl ethers was slower than the conversion of phenolic compounds (Tables 2, 3, and S5). This was caused by the fact that the conversion of di-aryl ethers was carried out in the presence of large concentrations of isopropanol (needed to dissolve the ether), which is expected to strongly solvate the ethers and strongly adsorb on the metal reducing the aryl ether coverage [24]. In line with this conclusion, the conversion of aryl ethers in $\mathrm{TCH}$ and $\mathrm{ECH}$ followed a first order dependence on the hydrocarbon (Figure S6), reflecting their low coverage. The conversion rates during $\mathrm{TCH}$ were higher than during $\mathrm{ECH}$ by factors of up to 1.7 (Table 3), which is attributed to differences in hydrogen coverage as shown for phenol. 
Although usage of organic solvents has profound effects on $\mathrm{ECH}$ rates (detail studies regarding the effect of solvent has been discussed in the supporting information), it does not affect HER strongly. Similarly, HER rates during the ECH of di-aryl ethers (performed in isopropanol-electrolyte mixtures) were between 33 and $42 \cdot 10^{-5} \mathrm{~mol} \cdot \mathrm{s}^{-1} \cdot \mathrm{g}_{\mathrm{Rh}}{ }^{-1}$, while the HER rate in phenol was $38 \cdot 10^{-5} \mathrm{~mol} \cdot \mathrm{s}^{-1} \cdot \mathrm{g}_{\mathrm{Rh}}{ }^{-1}$ at a potential of $-0.9 \mathrm{~V}$ ( $\mathrm{vs} \mathrm{Ag} / \mathrm{AgCl}$ ) (Tables 1 and 3).

Table 3. Current, current density, reaction rate, TOF, and Faradaic efficiency of the conversion of di-aryl ethers via electrocatalytic hydrogenation $(\mathrm{ECH})$ and thermal catalytic hydrogenation $(\mathrm{TCH})$. The reactions were performed in water-isopropanol mixtures at room temperature and atmospheric pressure on $\mathrm{Rh} / \mathrm{C}$.

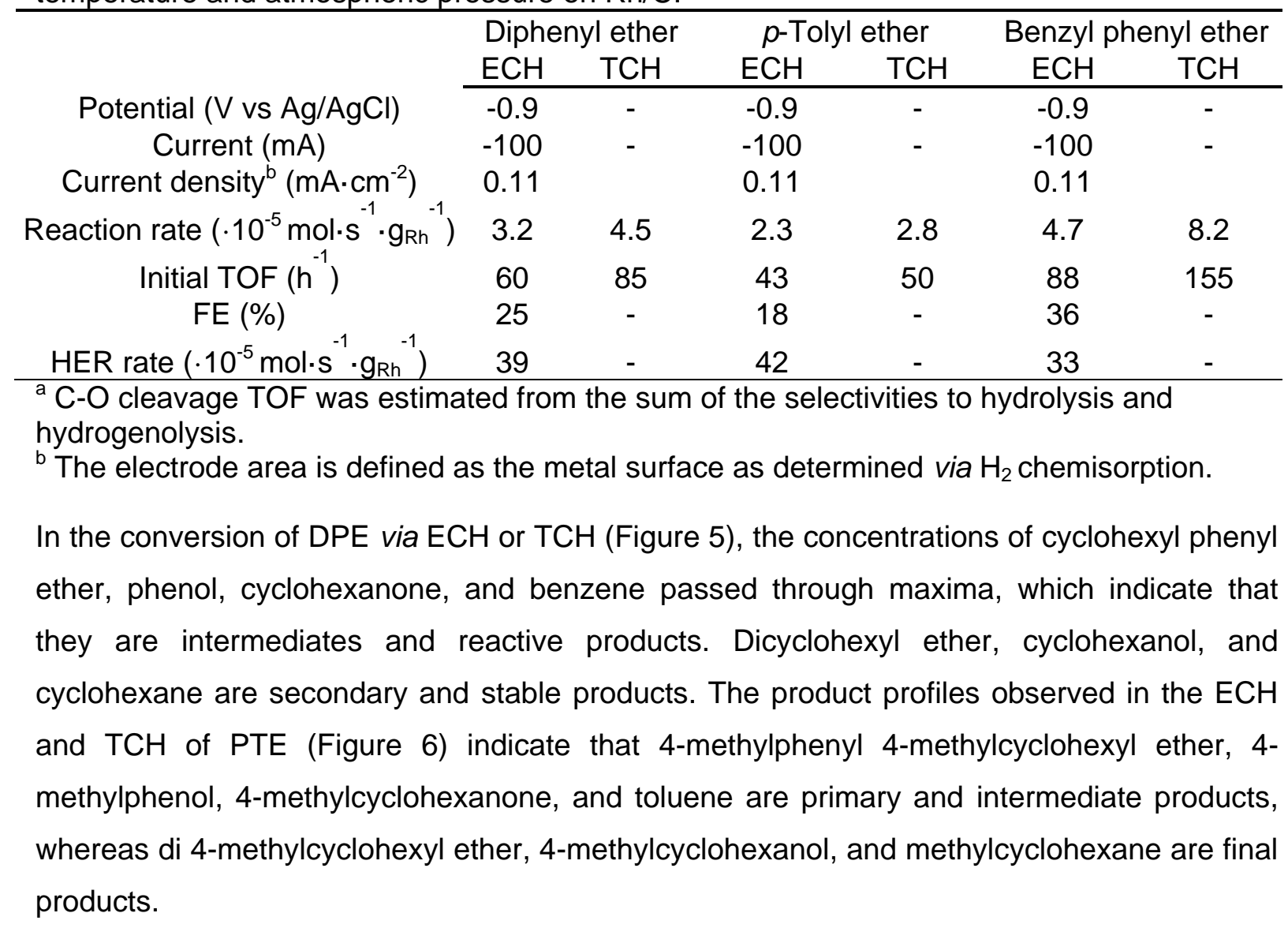




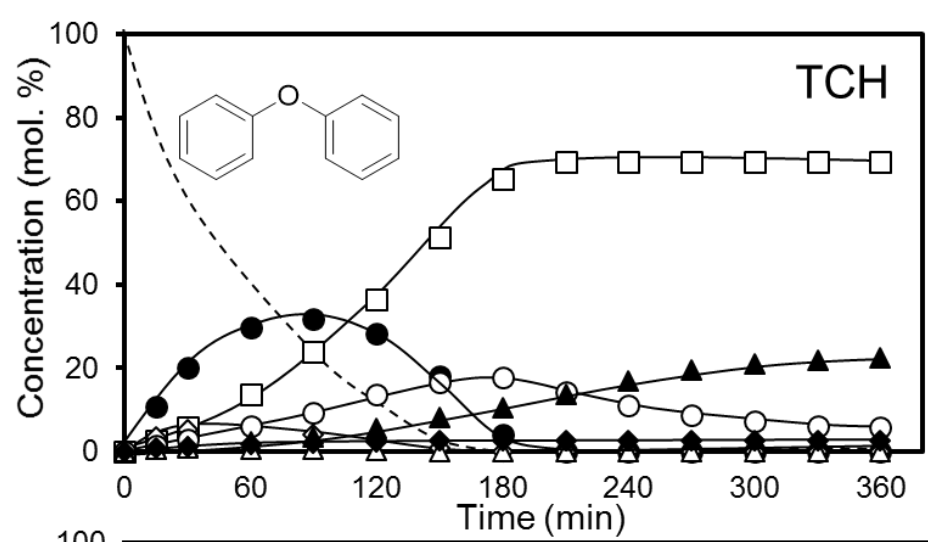

- Cyclohexyl phenyl ether

$\square$ Dicyclohexyl ether

$\diamond$ Phenol

OCyclohexanone

$\Delta$ Cyclohexanol

$\Delta$ Benzene

$\checkmark$ Cyclohexane

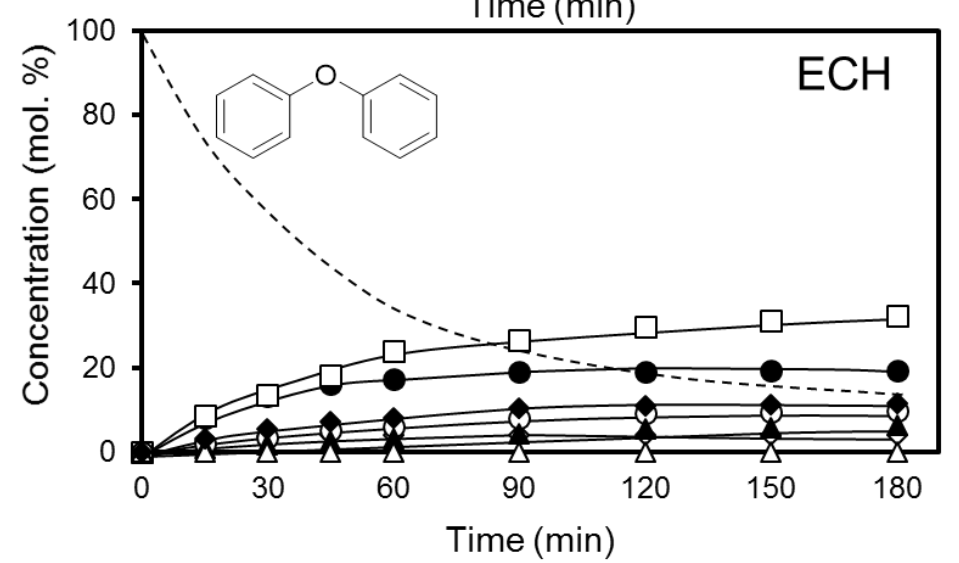

- Cyclohexyl phenyl ether

口Dicyclohexyl ether

$\diamond$ Phenol

oCyclohexanone

$\Delta$ Cyclohexanol

$\Delta$ Benzene

- Cyclohexane

Figure 5. Concentration profiles observed during catalytic thermal catalytic hydrogenation $(\mathrm{TCH})$ and electrocatalytic hydrogenation $(\mathrm{ECH})$ of diphenyl ether. The reactions were performed in water-isopropanol-acetic acid mixtures at room temperature and atmospheric pressure on $\mathrm{Rh} / \mathrm{C}$.

The products identified in the conversion of DPE and PTE point to three reaction pathways, i.e., hydrogenation (yielding hydrogenated ethers), hydrogenolysis, and hydrolysis (both yielding oxygenated as well as O-free hydrocarbons with only one aliphatic or aromatic ring). Hydrolysis was inferred by mass balances applied to the concentrations of the compounds with only one ring. The selectivity to the different pathways was similar for the conversions of DPE and PTE in ECH and TCH (Figure S7). This is attributed to the similarity of the structure and bond energies of both molecules and to identical elemental steps occurring on the metal surface under either $\mathrm{ECH}$ or $\mathrm{TCH}$.

Scheme 2 shows the reaction network for DPE and PTE and the selectivity to the different reaction pathways. In the hydrogenation route (selectivity of $\sim 70 \%$ ) both rings are hydrogenated in consecutive steps, each of them involving the addition of six hydrogen atoms. C-O bond cleavage does not occur on this route, which yields ethers as final products. In the hydrogenolysis route (selectivity of $7-13 \%$ ), a C-O bond is cleaved to produce phenolic and phenyl compounds as primary products, which are hydrogenated in subsequent parallel routes. The hydrolysis pathway (selectivity of $15-25 \%$ ) leads to phenolic compounds, which undergo consecutive hydrogenation yielding cyclic alcohols as final products (as shown for 
phenol and methylphenol in Scheme 1). Additional experiments using cyclohexyl phenyl ether, and 4-mehylphenyl 4-methylcyclohexyl as starting reactants showed that the C-O bond between benzyl and ether groups are cleaved yielding O-free aromatics and cyclic alcohols (indicated in Scheme 2 with the doted red line). The selectivity towards complete hydrogenation, however, from those partially hydrogenated ethers is higher than $90 \%$ (Figure S8 supporting information).
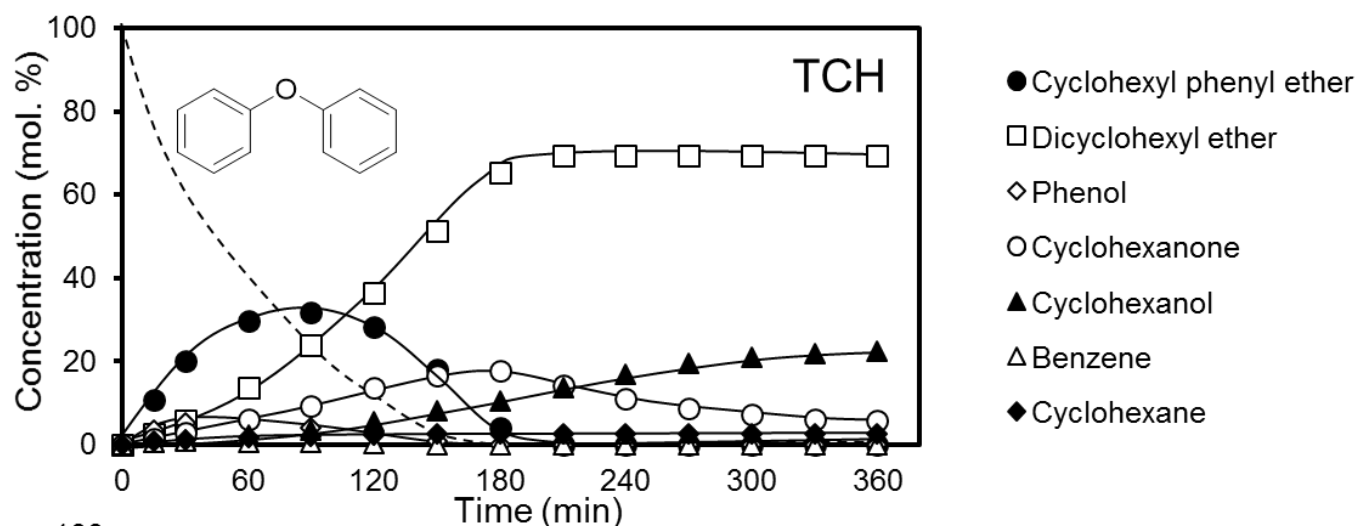

- Cyclohexane

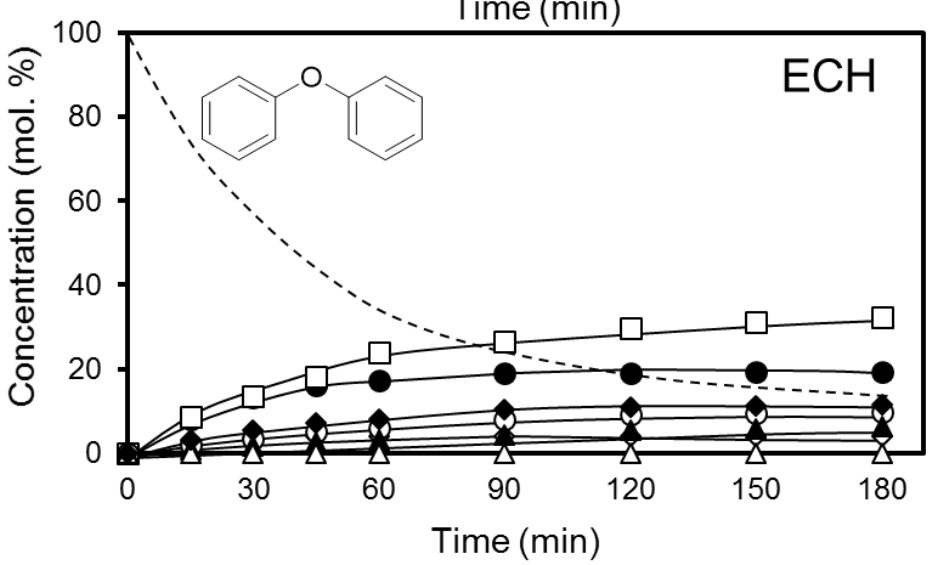

- Cyclohexyl phenyl ether 口Dicyclohexyl ether $\diamond$ Phenol oCyclohexanone $\Delta$ Cyclohexanol $\Delta$ Benzene - Cyclohexane

Figure 6. Concentration profiles observed during thermal catalytic hydrogenation $(\mathrm{TCH})$ and electrocatalytic hydrogenation $(E C H)$ of $p$-tolyl ether during of diphenyl ether. The reactions were performed in water-isopropanol-acetic acid mixtures at room temperature and atmospheric pressure on $\mathrm{Rh} / \mathrm{C}$. 


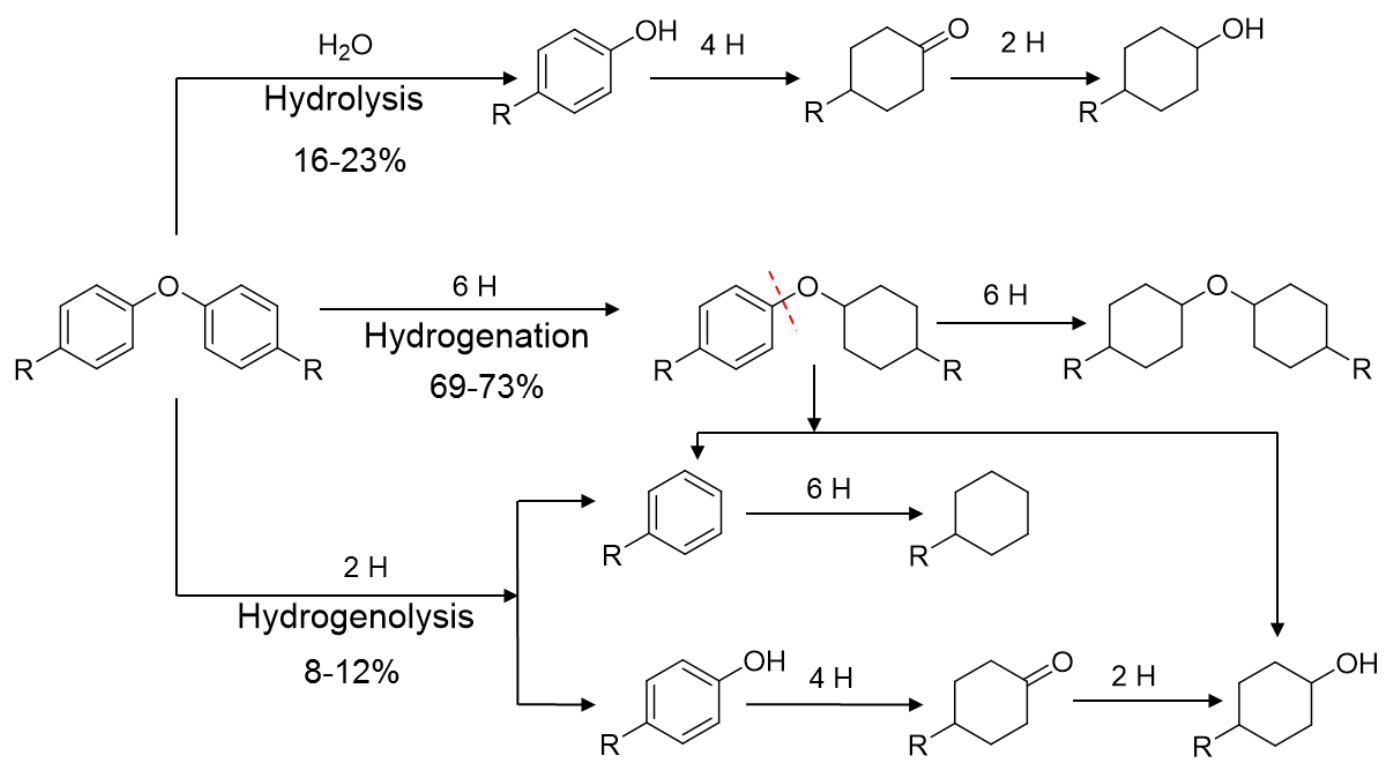

Scheme 2. Reaction network of the conversion of diphenyl ether $(R=H)$ and $p$-tolyl ether $\left(\mathrm{R}=\mathrm{CH}_{3}\right)$ under catalytic thermal hydrogenation and electrocatalytic hydrogenation.

The product profiles observed during the $\mathrm{TCH}$ and $\mathrm{ECH}$ of benzyl phenyl ether (BPE) are shown in Figure 7. The hydrogenated ethers, methyl cyclohexyl phenyl ether, cyclohexyl benzyl ether were primary and reactive products, whereas cyclohexyl methyl cyclohexyl ether was a stable product. Within the products with one functionalized ring, phenol, cyclohexanone, and benzyl alcohol, were secondary intermediates, whereas cyclohexanol, and cyclohexylmethanol were final products. The oxygen-free hydrocarbons toluene and methylcyclohexane were intermediate and final products, respectively. 


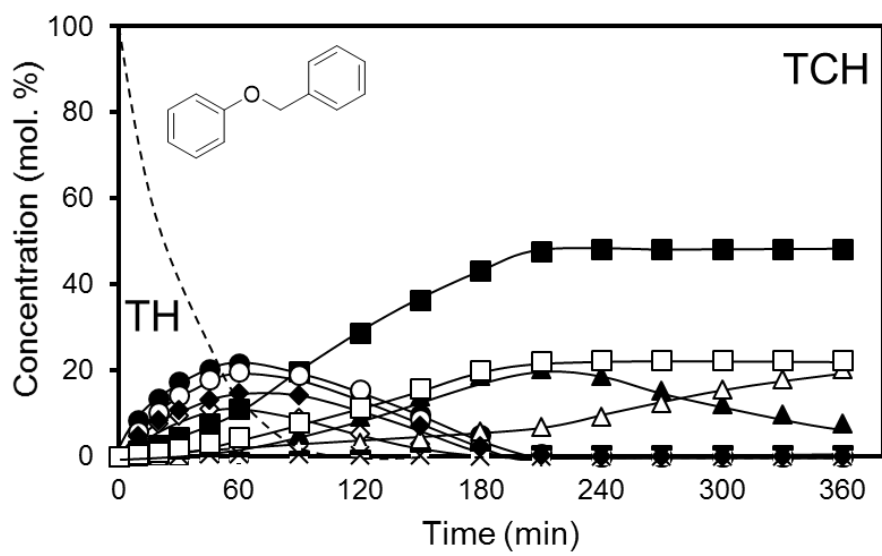

- Cyclohexyl benzyl ether

$\diamond$ Methylcyclohexyl phenyl ether

- Cyclohexyl methylcyclohexyl ether

OPhenol

$\Delta$ Cyclohexanone

$\triangle$ Cyclohexanol

xBenzyl alcohol

-Cyclohexylmethanol

- Toluene

$\square$ Methylcyclohexane

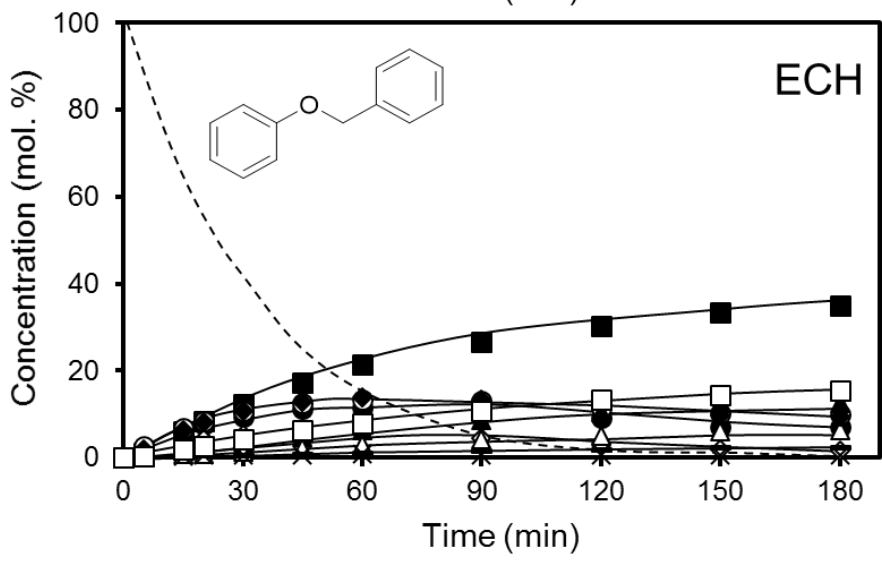

- Cyclohexyl benzyl ether

$\diamond$ Methylcyclohexyl phenyl ether

- Cyclohexyl methylcyclohexyl ether

OPhenol

$\Delta$ Cyclohexanone

$\triangle$ Cyclohexanol

XBenzyl alcohol

- Cyclohexylmethanol

- Toluene

$\square$ Methylcyclohexane

Figure 7. Concentration profiles observed during catalytic thermal hydrogenation of benzyl phenyl ether. The reactions were performed in a water-ethanol mixture at room temperature and atmospheric pressure on $\mathrm{Rh} / \mathrm{C}$.

The concentrations profiles and structure of the products allowed us to conclude that the conversion of BPE follows a reaction network that includes hydrogenation, hydrogenolysis, and hydrolysis as in the case of the symmetric ethers (Scheme 3). The selectivities to these three pathways in $\mathrm{ECH}$ and $\mathrm{TCH}$ are similar (Figure S7). The hydrogenation pathway (selectivity of $\sim 38 \%$ ) yields partially and fully hydrogenated ethers in consecutive steps. Cyclohexyl benzyl ether is the dominant primary product (over methyl cyclohexyl phenyl ether) suggesting that the phenyl ring is more facile to hydrogenate than the benzyl ring. This is because the $\mathrm{sp}^{3}$ hybridized $-\mathrm{CH}_{2}$ - group induces looser bonding of the aromatic ring to the surface. Hydrogenolysis (selectivity of $59-63 \%$ ) yields phenol and toluene on the cleavage of the $\alpha-\mathrm{O}-4$ bond. The same bond is cleaved by hydrolysis (selectivity of $\sim 2 \%$ ) yielding phenol and benzyl alcohol. The primary products of hydrogenolysis and hydrolysis undergo hydrogenation of the aromatic ring and carbonyl groups without further $\mathrm{C}-\mathrm{O}$ bond cleavage (as shown in Scheme 1 for phenol). Neither benzene nor cyclohexane were observed, indicating that the $\mathrm{C}_{\mathrm{sp}}{ }^{2}-\mathrm{O}$ bond in BPE was not cleaved. This is attributed to the large difference in bond energies, i.e., $218 \mathrm{~kJ} \cdot \mathrm{mol}^{-1}$ for $\mathrm{C}_{\mathrm{sp}}{ }^{3}-\mathrm{O}$ and $334 \mathrm{~kJ} \cdot \mathrm{mol}^{-1}$ for $\mathrm{C}_{\mathrm{sp}}{ }^{2}-\mathrm{O}$. 


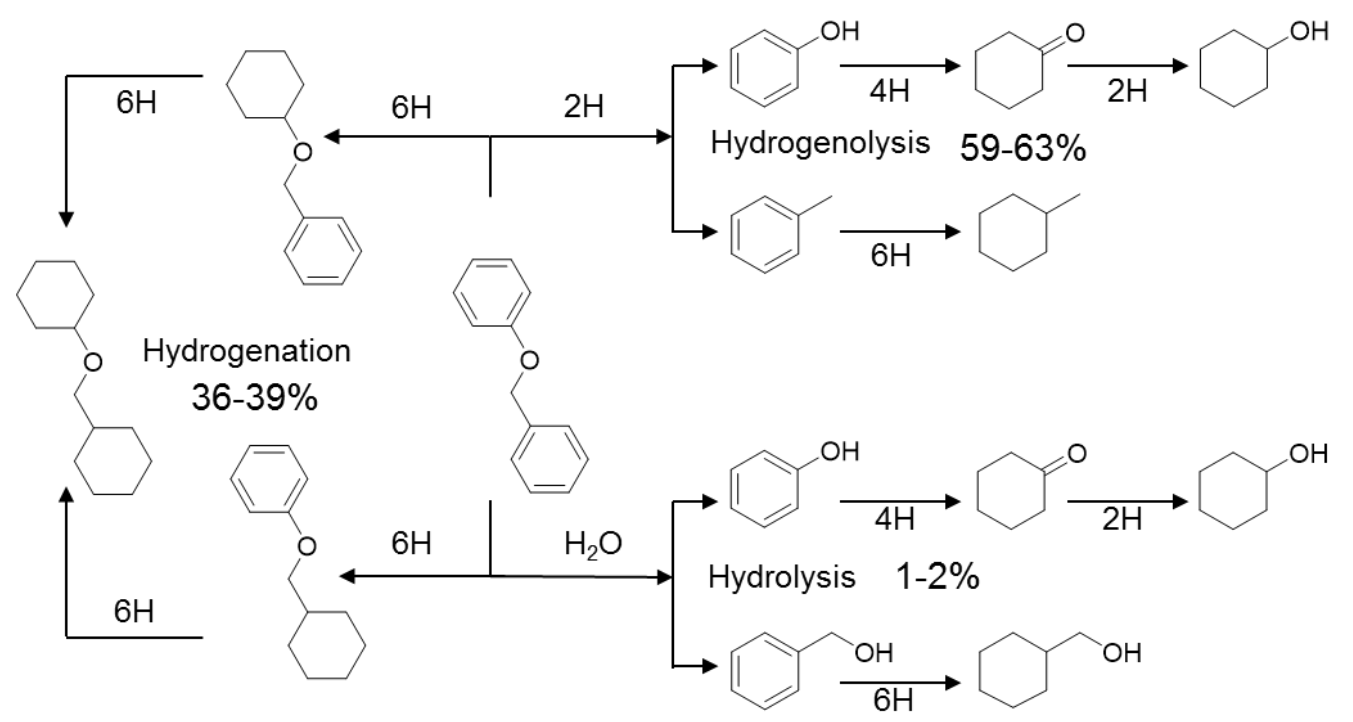

Scheme 3. Reaction network of the conversion of benzyl phenyl ether under catalytic thermal catalytic hydrogenation and electrocatalytic hydrogenation.

Let us analyze the particular initial conversion rates of the selected di-aryl ethers by ECH and $\mathrm{TCH}$ (Table 4). Comparisons between the rates of DPE and PTE conversion shows that the strong impact of the methyl groups on the adsorption of PTE is reflected in the rates of all pathways, which decreased by $20-50 \%$. BPE was converted much faster than DPE and PTE, mainly via hydrogenolysis, which proceeded at $4.7 \cdot 10^{-5} \mathrm{~mol} \cdot \mathrm{s}^{-1} \cdot \mathrm{g}_{\mathrm{Rh}}{ }^{-1}$ in $\mathrm{TCH}\left(2.1 \cdot 10^{-5} \mathrm{~mol} \cdot \mathrm{s}^{-}\right.$ ${ }^{1} \cdot \mathrm{g}_{\mathrm{Rh}}{ }^{-1}$ in $\left.\mathrm{ECH}\right)$. That is, from 4 to 8 times faster than the hydrogenolysis of DPE $\left(6 \cdot 10^{-6} \mathrm{~mol} \cdot \mathrm{s}^{-}\right.$ ${ }^{1} \cdot \mathrm{g}_{\mathrm{Rh}}{ }^{-1}$ in $\mathrm{TCH}$ and $5 \cdot 10^{-6} \mathrm{~mol} \cdot \mathrm{s}^{-1} \cdot \mathrm{g}_{\mathrm{Rh}}{ }^{-1}$ in $\mathrm{ECH}$ ) and from 5 to 19 times faster than the hydrogenolysis of PTE $\left(2.5 \cdot 10^{-6} \mathrm{~mol} \cdot \mathrm{s}^{-1} \cdot \mathrm{g}_{\mathrm{Rh}}{ }^{-1}\right.$ in $\mathrm{TCH}$ and $4 \cdot 10^{-6} \mathrm{~mol} \cdot \mathrm{s}^{-1} \cdot \mathrm{g}_{\mathrm{Rh}}{ }^{-1}$ in $\left.\mathrm{ECH}\right)$. In contrast, the hydrogenation rate of BPE was identical to that of DPE $\left(\sim 3.3 \cdot 10^{-5} \mathrm{~mol} \cdot \mathrm{s}^{-1} \cdot \mathrm{g}_{\mathrm{Rh}}{ }^{-1}\right.$ in $\mathrm{TCH}$ and $\sim 2.5 \cdot 10^{-5} \mathrm{~mol} \cdot \mathrm{s}^{-1} \cdot \mathrm{g}_{\mathrm{Rh}}{ }^{-1}$ in $\left.\mathrm{ECH}\right)$. Hence, the hydrogenation of the aromatic rings is not influenced by the presence of the methylene bridge group. The rates of BPE hydrolysis $\left(1 \cdot 10^{-6} \mathrm{~mol} \cdot \mathrm{s}^{-1} \cdot \mathrm{g}_{\mathrm{Rh}}{ }^{-1}\right.$ in TCH and $\left.\mathrm{ECH}\right)$ are lower than those of DPE $\left(7 \cdot 10^{-6} \mathrm{~mol} \cdot \mathrm{s}^{-1} \cdot \mathrm{g}_{\mathrm{Rh}}{ }^{-1}\right.$ in TCH and $3 \cdot 10^{-6} \mathrm{~mol} \cdot \mathrm{s}^{-1} \cdot \mathrm{g}_{\mathrm{Rh}}{ }^{-1}$ in $\left.\mathrm{ECH}\right)$ and even lower than those of PTE $\left(6 \cdot 10^{-6} \mathrm{~mol} \cdot \mathrm{s}^{-1} \cdot \mathrm{g}_{\mathrm{Rh}}{ }^{-1}\right.$ in TCH and $2 \cdot 10^{-6} \mathrm{~mol} \cdot \mathrm{s}^{-1} \cdot \mathrm{g}_{\mathrm{Rh}}{ }^{-1}$ in $\left.\mathrm{ECH}\right)$. This is attributed to the preference of a $\mathrm{PhCH}_{2} \cdot$ fragment to combine with $\mathrm{H}$. but not $\mathrm{OH}$. [25]. We note in passing that hydrolysis did not occur in the absence of adsorbed hydrogen (via $\mathrm{H}_{2}$ dissociation or $\mathrm{H}^{+}$reduction). Thus, the $\mathrm{C}-\mathrm{O}$ cleavage for hydrolysis appears to be related to that in hydrogenolysis, whereas the difference relates to the probability of $\mathrm{H}$. or $\mathrm{OH}$. being added to the adsorbed hydrocarbon moiety [25].

Table 4. Reaction rate $\left(\mathrm{mol} \cdot \mathrm{s}^{-1} \cdot \mathrm{g}_{\mathrm{Rh}}{ }^{-1}\right.$ ) of di-aryl ethers via different pathways in electrocatalytic hydrogenation. The reactions were performed in a water-isopropanol-acetic acid mixture at room temperature and atmospheric pressure on $\mathrm{Rh} / \mathrm{C}$. 


\begin{tabular}{ccccccc}
\hline & \multicolumn{2}{c}{ Hydrogenation } & \multicolumn{2}{c}{ Hydrolysis } & \multicolumn{2}{c}{ Hydrogenolysis } \\
\cline { 2 - 7 } & ECH & TCH & ECH & TCH & ECH & TCH \\
\cline { 2 - 7 } DPE & $2.4 \cdot 10^{-5}$ & $3.2 \cdot 10^{-5}$ & $3 \cdot 10^{-6}$ & $7 \cdot 10^{-6}$ & $5 \cdot 10^{-6}$ & $6 \cdot 10^{-6}$ \\
PTE & $1.6 \cdot 10^{-5}$ & $1.9 \cdot 10^{-5}$ & $2 \cdot 10^{-6}$ & $6 \cdot 10^{-6}$ & $4 \cdot 10^{-6}$ & $2.5 \cdot 10^{-6}$ \\
BPE & $2.5 \cdot 10^{-5}$ & $3.4 \cdot 10^{-5}$ & $1 \cdot 10^{-6}$ & $1 \cdot 10^{-6}$ & $2.1 \cdot 10^{-5}$ & $4.7 \cdot 10^{-5}$ \\
\hline
\end{tabular}

\section{Coupling electrocatalytic and catalytic conversion.}

We have established that the rates of $\mathrm{ECH}$ increase with increasingly negative potentials due to changes in the concentration of adsorbed hydrogen. At potentials less negative than -0.9 $\mathrm{V}$, the hydrogen coverages are low $\left(-0.7 \mathrm{~V}\right.$ equals to only 1 bar $\mathrm{H}_{2}$ pressure). Thus, we hypothesized that the Tafel step could be reverted even with small $\mathrm{H}_{2}$ pressure increases in order to increase the concentration of adsorbed hydrogen. In order to test this hypothesis, ECH was performed at optimum conditions keeping the $\mathrm{H}_{2}$ ex HER in the reaction media, while monitoring the associated pressure increase. Namely, combined ECH/TCH experiments of phenol and PTE (the most reactive compound and the least reactive compound, respectively, used in this study) at -0.7 and $-0.9 \mathrm{~V}$, respectively, while recycling the evolved $\mathrm{H}_{2}$ into the reactor.

Under normal ECH conditions, the conversion of phenol increased linearly, which leads to a constant TOF along the whole experiment. In contrast, with increasing $\mathrm{H}_{2}$ pressure the conversion increases with time because the TOF increases as the coverage of $\mathrm{H}$ increases (Figure 8). As the reaction is zero order in phenol, we could directly correlate the increase in rates in the $\mathrm{ECH} / \mathrm{TCH}$ experiments with the pressure of $\mathrm{H}_{2}$ accumulated in the reactor. The increases in rate exhibited a reaction order of 1.5 on $\mathrm{H}_{2}$ pressure (Figure S9), which confirms that the coverage of hydrogen is low under $\mathrm{ECH}$ conditions (at $-0.7 \mathrm{~V}$ ). In the case of $\mathrm{ECH}$ of PTE at normal conditions, the conversion decreased with time due to deactivation and the TOF rapidly decreased. In the presence of increasing $\mathrm{H}_{2}$ pressure, the increases in rate also exhibited a reaction order of 1.5 on $\mathrm{H}_{2}$ pressure, whereas the conversion followed first order kinetics with an apparent rate constant of $17 \mathrm{~h}^{-1}$. This indicates that increasing the coverage of hydrogen at the surface compensates the effect of low hydrocarbon coverages for the hydrogenation rates. 

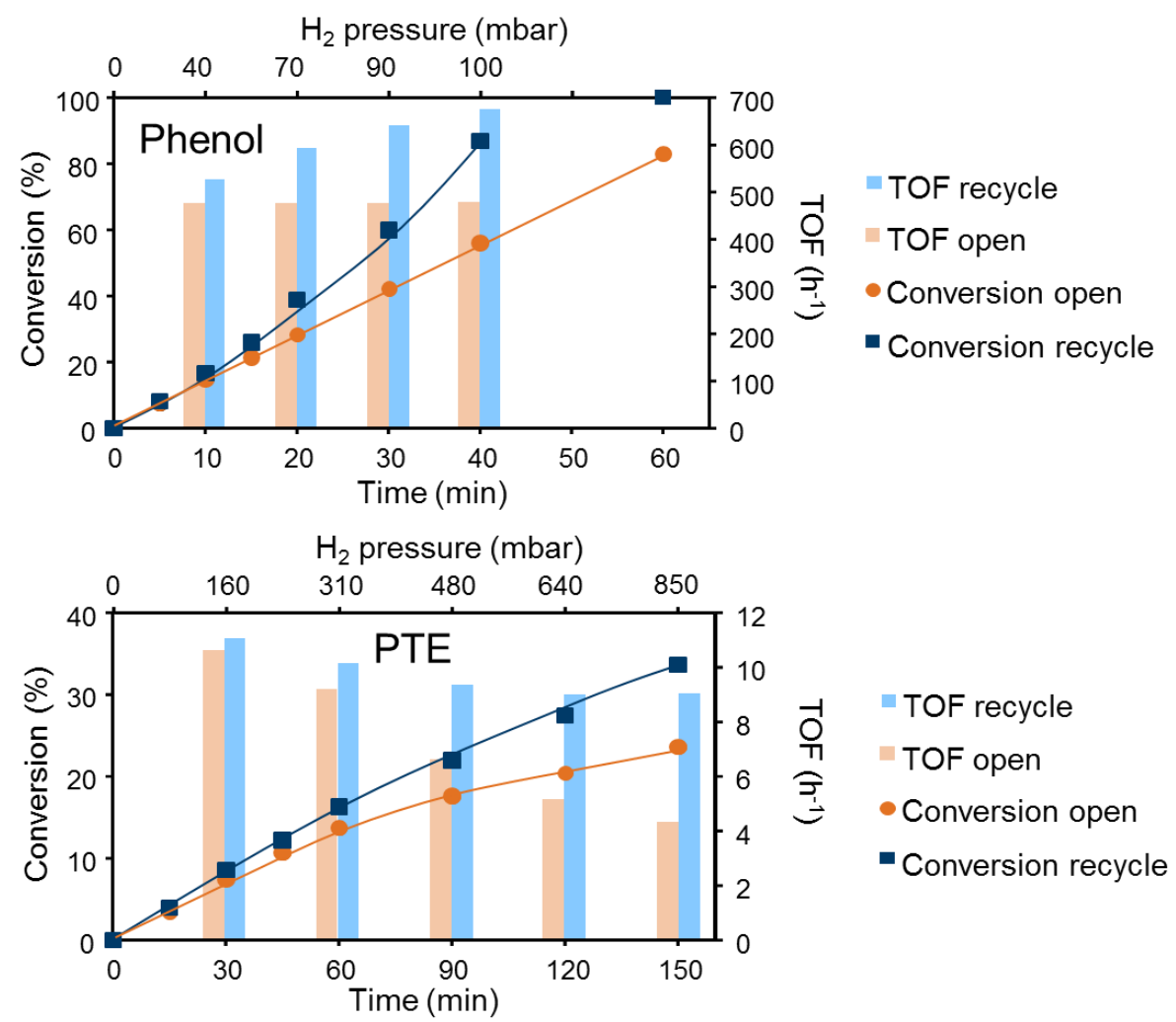

Figure 8. Comparison of electrocatalytic reduction of phenol and p-tolyl ether (PTE) (at - $0.7 \mathrm{~V}$ and $-0.9 \mathrm{~V}$, respectively). Orange columns, lines and symbols represent results obtained at normal ECH conditions. Blue columns, lines and symbols represent results obtained when recycling the evolved $\mathrm{H}_{2}$.

\section{Conclusions}

The rates of electrocatalytic hydrogenation $(\mathrm{ECH})$ of functionalized aromatic molecules on carbon supported $\mathrm{Rh}$ are proportional to the negative potential of the electrode at ambient reaction conditions. Reaction rates of $\mathrm{ECH}$ rise with increasing cathodic potentials (above the potential needed for $\mathrm{H}_{2}$ evolution) up to values that trigger the formation of compounds that adsorb strongly on the metal. ECH rates were higher than those of thermal catalytic hydrogenation $(\mathrm{TCH})$. The concentration of adsorbed hydrogen can be sustained at values above that corresponding to 1 bar $\mathrm{H}_{2}$ by employing higher cathodic potentials. This coverage, however, seems low and can be increased by keeping $\mathrm{H}_{2}$ (ex- $\mathrm{H}_{2}$ evolution reaction) in the reaction media favoring the inverse Tafel step to aid the oxygenate transformation instead of competing with it.

Electrocatalytic and thermal hydrogenation of phenolic compounds and diaryl ethers follow identical routes, i.e., hydrogenation, hydrogenolysis, and hydrolysis, with similar selectivity. Comparison with high temperature hydrodeoxygenation studies allows concluding that the 
presence of substituents in the aromatic rings reduces $\mathrm{ECH}$ and $\mathrm{TCH}$ rates due to repulsion with the metal, whereas the rate of $\mathrm{C}-\mathrm{O}$ bond cleavage is inversely proportional to the corresponding bond energy. Hydrogenation, the dominant route (the only one for phenol and methylphenol), yields cyclic alcohols and cycloalkyl ethers as final products. Hydrogenolysis and hydrolysis (minor pathway) allow C-O bond cleavage of methoxy groups and ether bonds. This allows obtaining O-free hydrocarbons in a reaction path, which can reach significant selectivities.

\section{Acknowledgements}

The authors would like to thank the group of Prof. Hubert A. Gasteiger at the Technische Universität München and the group of Prof. Jorge Gascon at the Delft University of Technology for scientific and technical advice. The authors are grateful to Nirala Singh, Donald M. Camaioni, Philipp Rheinländer, Erika Ember, Robert Weber, Gary Haller, Hany ElSayed, Juan Herranz Salaner, and Constantinos Vayenas for fruitful discussions. We are also grateful to Marianne Hanzlik for TEM measurements and to Xaver Hecht and Martin Neukamm for technical support. Yang Song would like to thank the Chinese Scholarship Council for the financial support. J.A.L. acknowledges support for his contribution by the Laboratory Directed Research and Development Program at Pacific Northwest National Laboratory, a multi-program national laboratory operated by Battelle for the U.S. Department of Energy.

\section{References}

[1] M. Chatterjee, T. Ishizaka, A. Suzuki, H. Kawanimi, Chem. Commun. 49 (2013) 45674569.

[2] S. Czernik, A.V. Bridgwater, Energy Fuels. 18 (2004) 590-598.

[3] C. Zhao, Y. Kou, A.A. Lemonidou, X. Li, J.A. Lercher, Angew. Chem. Int. Ed. 48 (2009) 4047-4050.

[4] M. Chatterjee, A. Chatterjee, T. Ishizaka, H. Kawanami, Catal. Sci. Technol. 5 (2015) 1532-1539.

[5] A. J. Ragauskas, C. K. Williams, B. H. Davison, G. Britovsek, J. Cairney, C. A. Eckert, W. J. Frederick, J. P. Hallett, D. J. Leak, C. L. Liotta, J. R. Mielenz, R. Murphy, R. Templer, T. Tschaplinski, Science 311 (2006) 484-489.

[6] S. J. Davis, K. Caldeira, H. D. Matthews, Science 329 (2010) 1330-1333.

[7] A. Corma, S. Iborra, A. Velty, Chem. Rev. 107 (2007) 2411-2502. 
[8] X. Wang, R. Rinaldi, Energy Environ. Sci. 5 (2012) 8244-8260.

[9] J. Mortensen, J. Heinze, Angew. Chem. Int. Ed. Engl. 23 (1984) 84-85.

[10] M. Bourrez, R. Steinmetz, S. Ott, F. Gloaguen, L. Hammarström, Nat. Chem. 7 (2015) 140-145.

[11] D. Weinberg, C. Gagliardi, J. Hull, C. Murphy, C. Kent, B. Westlake, A. Paul, D. Ess, D. McCafferty, T. Meyer, Chem. Rev. 112 (2012) 4016-4093

[12] M. Hang, V. Huynh, T. Meyer, Chem. Rev. 107 (2007) 5004-5064.

[13] Y. Song, O. Gutiérrez, J. Herranz, J. A. Lercher, Appl. Catal. B. 182 (2016) 236-246.

[14] C. Cirtiu, H. Hassani, N. Bouchard, P. A. Rowntree, H. Ménard, Langmuir. 22 (2006) 6414-6421.

[15] C. M. Cirtiu, A. Brisach-Wittmeyer, H. Ménard, Catal. Commun. 8 (2007) 751-754.

[16] J.J. Roylance, K.-S. Choi, Green Chem. DOI: 10.1039/c6gc00533k.

[17] S. J. Jenkins, Proc. R. Soc. A. 465 (2009) 2949-2976.

[18] B. Güvenatam, O. Kurşun, E. H. Heeres, E. A. Pidko, E. J. Hensen, Catal. Today. 233 (2014) 83-91.

[19] D. J. Rensel, S. Rouvimov, M. E. Gin, J. C. Hicks, J. Catal. 305 (2013) 256-263.

[20] C. Lam, C. Lowe, Z. Li, K .Longe, J. Rayburn, M. Caldwell, C. Houdek, J. Maguire, C. Saffron, D. Miller, H. Jackson, Green. Chem. 17 (2015) 601-609.

[21] X. Wang, R. Rinaldi, ChemSusChem. 5 (2012) 1455-1466.

[22] W. Wu, J. Huang, J. Org. Chem. 79 (2014) 10189-10195.

[23] J. He, C. Zhao, D. Mei, J.A. Lercher, J Catal. 309 (2014) 280-290.

[24] J. He, C. Zhao, J.A. Lercher, J Catal. 309 (2014) 362-375.

[25] J. He, C. Zhao, J. Lercher, J. Am. Chem. Soc.134 (2012) 20768-20775. 


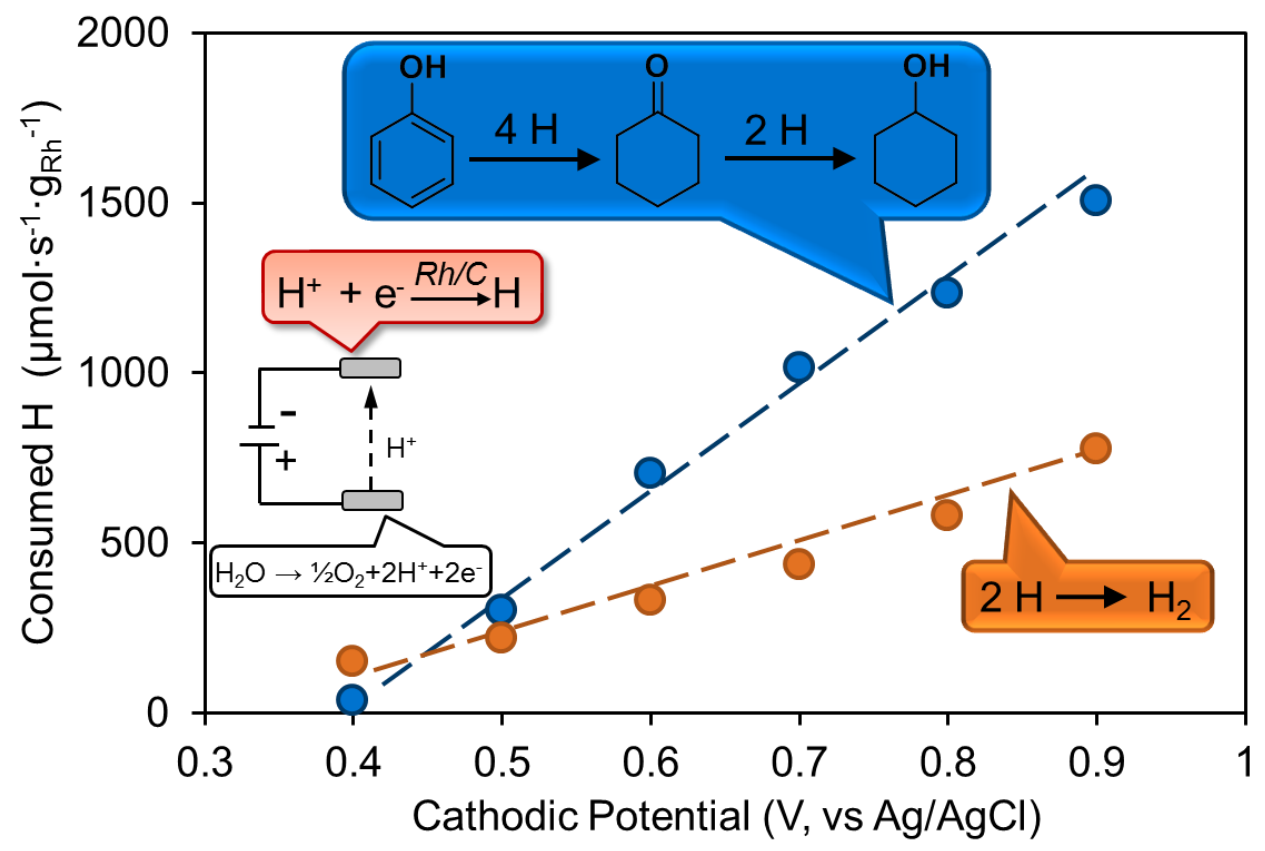

\section{Graphical Abstract}

Electrocatalytic hydrogenation $(\mathrm{ECH})$ of phenolic compounds and diaryl ethers was explored on $\mathrm{Rh} / \mathrm{C}$ at room temperature and atmospheric pressure in the absence of external $\mathrm{H}_{2}$. The dominant reaction pathway is hydrogenation of the aromatic rings, although methoxy and benzyloxy groups can undergo $\mathrm{C}-\mathrm{O}$ bond cleavage. Increasing cathodic potentials favors the rates of $\mathrm{ECH}$ over $\mathrm{H}_{2}$ evolution. The coverage of adsorbed $\mathrm{H}$ is further increased by generating a $\mathrm{H}_{2}$ atmosphere enhancing hydrogenation rates. 